\title{
On the Development of a New Nonequilibrium Chemistry Model for Mars Entry
}

R. L. Jaffe ${ }^{a}$, D. W. Schwenke ${ }^{a}$, G. M. Chabana,

D. K. Prabhua , C. O. Johnston ${ }^{b}$ and M. Panesic aNASA Ames Research Center bNASA Langley Research Center

cUniversity of Illinois at Urbana-Champaign

AIAA SciTech 2017

January 11, 2017 


\section{Motivation}

- NASA has been embarked on a program of scientific exploration of Mars by landing increasingly larger and heavier payloads

- Prediction of thermal load used to determine TPS requirements

- Testing in ground facilities and CFD simulations play critical roles

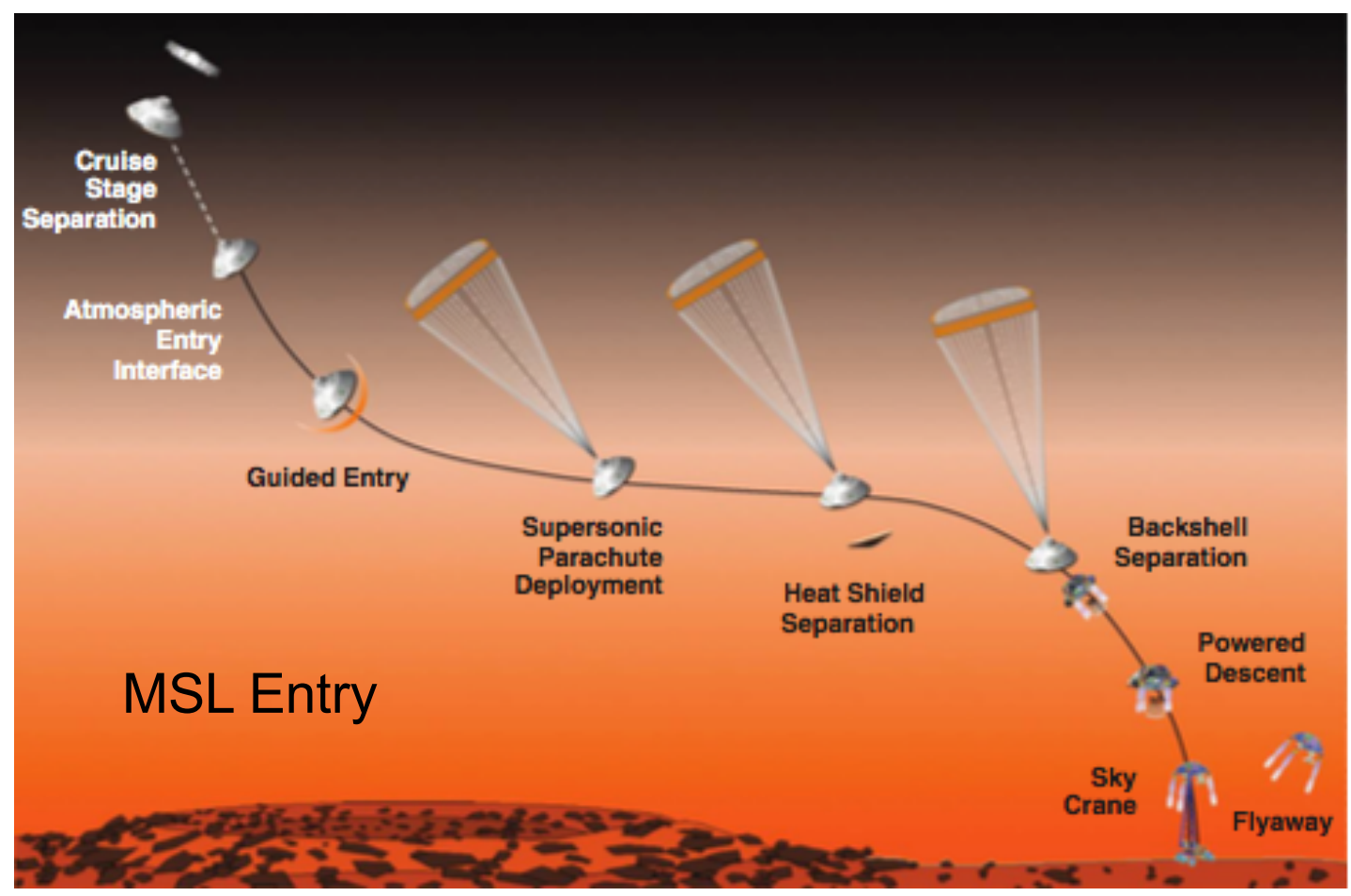

Nonequilibrium chemistry model currently in use is $20+$ years old and based on mostly $35+$ year old experiments

We are critically examining this "legacy" model and developing a new model based on computational chemistry and physics

Our objective is to reduce the uncertainty in predictions of thermal loads for Mars entry 


\section{Outline}

- Legacy nonequilibrium chemistry model

- Computational approach for developing a new model

- Rate Coefficients

- Chemical rections for Mars entry

- Uncertainty Quantification

- CO dissociation

- Comparison with other models

- Convective heating

- Radiative Flux

- Next steps in developing the nonequilibrium chemistry model

- Conclusions 


\section{Legacy Mars Chemistry Model}

- Nonequilibrium between translational and internal energy modes of the flowfield species in the bow shock layer

- After shock wave gas is compressed and heated

- Two temperatures $\left(T=T_{r}\right.$ and $\left.T_{v}=T_{\text {el-st }}\right)$

- First order relaxation equation describes evolution of $T_{v}$ from the shock to thermal equilibrium $\left(T_{v}=T\right)$; governed by relaxation time $\tau_{v}$

- Dissociation reactions modeled by Arrhenius rate expression using an average temperature $T_{a v}=\left(T \cdot T_{v}\right)^{1 / 2}$

- Rate coefficient parameters originally taken from 1960's-70's shock tube experiments, but subjected to empirical adjustment

- Developed by Chul Park at NASA Ames 1986-1992 (Park et al, JTHT 8, 9-23 (1994))

- Recent modification of parameters by Johnston and Brandis (JSQRT 149, 303-317 (2014)) 


\section{Mars Entry: What Collisional Processes are Important?}

- Mars atmosphere is $\sim 96 \% \mathrm{CO}_{2}, \sim 2 \% \mathrm{~N}_{2} \sim 2 \% \mathrm{Ar}$

- Dissociation

- $\mathrm{CO}_{2}(5 \mathrm{eV})$ very fast and nearly complete

- CO $(11 \mathrm{eV})$ slow, rate determining process

- Heterogeneous exchange reactions provide lower energy (i.e. faster) routes for $\mathrm{CO}_{2}$ and $\mathrm{CO}$ dissociation

$-\mathrm{CO}_{2}+\mathrm{O} \rightarrow \mathrm{CO}+\mathrm{O}_{2}$

$-\mathrm{CO}+\mathrm{O} \rightarrow \mathrm{C}+\mathrm{O}_{2}$

$-\mathrm{CO}+\mathrm{N} \rightarrow \mathrm{O}+\mathrm{CN}$

$-\mathrm{CO}+\mathrm{C} \rightarrow \mathrm{O}+\mathrm{C}_{2}$

For Mars entry at 6-8 km/s, the rate of CO dissociation is critical because $\mathrm{CO} 4^{\text {th }}$ positive emission is the dominant source of radiative heating 


\section{New Paradigm for a Nonequilibrium Chemistry Model}

- Accurate quantum mechanics calculations to quantify interaction energy between atoms and molecules

- Potential Energy Surface (PES) obtained from solution of Schrödinger equation

- Repeated for many geometric arrangements of the atoms (for $n$ atoms there are $3 n-6$ degrees of freedom)

- Goal is $\leq \pm 5 \mathrm{~kJ} / \mathrm{mol}$ relative accuracy $\left(\sim 0.05 \mathrm{eV}, \sim 400 \mathrm{~cm}^{-1}\right)$

- Classical mechanics simulations of heavy particle collisions to compute collision cross sections and rate coefficients

- Compute trajectories of many individual collisions (Quasi-Classical Trajectory or QCT calculation)

- Monte Carlo sampling used reproduce random or thermal collisional distributions

This strategy should yield rate coefficients accurate to $\pm 20 \%$

(Ref: Jaffe et al. "First principles calculation of heavy particle rate coefficients" in "Hypersonic nonequilibrium Flows: Fundamentals and Recent Advances", E. Josyula, ed, AIAA 2015) 


\section{Important Chemical Reactions for Mars Entry ${ }^{\mathbf{~}}{ }_{\text {inea }}$}

\begin{tabular}{|c|c|c|c|c|}
\hline & Reaction & Experiment & PES & QCT rate coeff. \\
\hline D1 & $\begin{array}{l}\mathrm{CO}_{2}+\mathrm{M} \rightarrow \mathrm{CO}+\mathrm{O}+ \\
\mathrm{M} \\
\mathrm{M}=\mathrm{CO}_{2}, \mathrm{~N}_{2}, \mathrm{CO}, \mathrm{O}\end{array}$ & $\begin{array}{l}\text { Shocktube expts } \\
1968-74 \& 1984\end{array}$ & & \\
\hline$D 2$ & $\begin{array}{l}\mathrm{CO}+M \rightarrow C+\mathrm{O}+\mathrm{M} \\
M=\mathrm{CO}, \mathrm{O}\end{array}$ & $\begin{array}{l}\text { Shocktube expts } \\
1968-74 \text { \& } 1984\end{array}$ & NASA Ames 2016 & NASA Ames 2016 \\
\hline 米D3 & $\begin{array}{l}\mathrm{N}_{2}+\mathrm{M} \rightarrow \mathrm{N}+\mathrm{N}+\mathrm{M} \\
\mathrm{M}=\mathrm{N}_{2}, \mathrm{~N}\end{array}$ & $\begin{array}{l}\text { Shocktube expts } \\
1964-74 \text { \& } 1993\end{array}$ & $\begin{array}{l}\text { NASA Ames } 2010 \\
\text { U. Minnesota } 2013\end{array}$ & $\begin{array}{l}\text { NASA Ames 2010-16 } \\
\text { U. Minn. 2013-16 }\end{array}$ \\
\hline 米D4 & $\begin{array}{l}\mathrm{O}_{2}+\mathrm{M} \rightarrow \mathrm{O}+\mathrm{O}+\mathrm{M} \\
\mathrm{M}=\mathrm{N}_{2}, \mathrm{CO}, \mathrm{O}\end{array}$ & $\begin{array}{l}\text { Expts 1960s, } 84 \\
\text { Hanson } 2016\end{array}$ & $\begin{array}{l}\text { Varandas } 1988 \\
\text { Dawes 2011-13 }\end{array}$ & Andrienko 2016 \\
\hline E1 & $\mathrm{CO}_{2}+\mathrm{O} \rightarrow \mathrm{CO}+\mathrm{O}_{2}$ & Ibragimova 1991 & & \\
\hline E2 & $\mathrm{CO}+\mathrm{O} \rightarrow \mathrm{C}+\mathrm{O}_{2}$ & Hanson 1991 & NASA Ames 2016 & NASA Ames 2016 \\
\hline 米E3 & $\mathrm{N}_{2}+\mathrm{O} \rightarrow \mathrm{NO}+\mathrm{N}$ & $\begin{array}{l}\text { Michael } 1992 \\
\text { Roth } 1985\end{array}$ & Sayos 2003-16 & $\begin{array}{l}\text { Sayos 2010-12 } \\
\text { U. Minn } 2016\end{array}$ \\
\hline 米E4 & $\mathrm{NO}+\mathrm{O} \rightarrow \mathrm{O}_{2}+\mathrm{N}$ & Fontijn 1998 & Sayos 2002 & Sayos 2003 \\
\hline E5 & $\mathrm{CO}+\mathrm{N} \rightarrow \mathrm{CN}+\mathrm{O}$ & & Nyman 2000-2008 & \\
\hline E6 & $\mathrm{CO}+\mathrm{N} \rightarrow \mathrm{NO}+\mathrm{C}$ & & Nyman 2000-2008 & \\
\hline E7 & $\mathrm{CN}+\mathrm{O} \rightarrow \mathrm{NO}+\mathrm{C}$ & Roth 1990 & Nyman 2000-2008 & \\
\hline E8 & $\mathrm{CO}+\mathrm{C} \rightarrow \mathrm{C}_{2}+\mathrm{O}$ & & & \\
\hline
\end{tabular}




\section{Uncertainty Quantification (UQ)}

- UQ used to identify critical reactions

- Monte Carlo sensitivity analysis

- $96 \% \mathrm{CO}_{2} / 4 \% \mathrm{~N}_{2}$ (free stream at 0.25 torr and $300 \mathrm{~K}$ )

- 1-d shock at $7.75 \mathrm{~km} / \mathrm{s}$

- Random sampling of rate coefficient and vibrational relaxation parameters

- Two criteria considered: sensitivity to $\mathrm{CO} 4^{\text {th }}$ positive radiative intensity and sensitivity to attaining chemical equilibrium $\left(\mathrm{T} / \mathrm{T}_{\mathrm{eq}}=1.05\right)$

- Repeated many times for statistical analysis

- Key reactions:

\begin{tabular}{|c|c|c|}
\hline Reaction & Sensitivity to Radiative Flux & Sensitivity to Equilibration Time \\
\hline $\mathrm{CO}+\mathrm{O} \rightarrow \mathrm{C}+\mathrm{O}+\mathrm{O}$ & $55 \%$ & $48 \%$ \\
\hline $\mathrm{CO}+\mathrm{CO} \rightarrow \mathrm{C}+\mathrm{O}+\mathrm{CO}$ & $25 \%$ & $10 \%$ \\
\hline $\mathrm{CN}+\mathrm{O} \rightarrow \mathrm{C}+\mathrm{NO}$ & $9 \%$ & $24 \%$ \\
\hline $\mathrm{CO}+\mathrm{O} \rightarrow \mathrm{C}+\mathrm{O}_{2}$ & $4 \%$ & $8 \%$ \\
\hline
\end{tabular}




\section{CO Dissociation}

- The radiative heat flux experienced by spacecraft entering the Martian atmosphere at $5-8 \mathrm{~km} / \mathrm{s}$ is mostly due to the $\mathrm{CO} 4^{\text {th }}$ positive band system $(\lambda<200 \mathrm{~nm})$

- Radiative heating is therefore proportional to the mole fraction of $\mathrm{CO}$ in the bow shock layer

- CFD-Radiative transport calculations using the T- $T_{v}$ model (legacy Mars chemistry model) predict greater radiance than observed in tests run in the Electric Arc Shock Tube (EAST) at Ames

- Johnston and Brandis (JQSRT, 2014) scaled some of the rate coefficient parameters to force agreement between CFD and EAST for $\mathrm{CO} 4^{\text {th }}$ positive

- Ab initio PESs have been computed for $\mathrm{CO}+\mathrm{Ar}$ and $\mathrm{CO}+\mathrm{O}$ and used in QCT calculations of CO dissociation rate coefficients (Schwenke et al., J Chem. Phys. submitted )

- Experimental data for $\mathrm{CO}+\mathrm{Ar}$ seem more reliable than for $\mathrm{CO}+\mathrm{O}$

- Efficiency of different collision partners (M) for promoting dissociation has been expressed as ratio $\mathrm{k}(\mathrm{CO}+\mathrm{M}) / \mathrm{k}(\mathrm{CO}+\mathrm{Ar})$ 


\section{Rate Coefficient Ratios for CO Dissociation}

- Early experimental values (Baulch, based on pre-1972 shock tube experiments)

- $\mathrm{k}_{\mathrm{CO}+\mathrm{CO}} / \mathrm{k}_{\mathrm{CO}+\mathrm{Ar}}=1-2 \quad \mathrm{k}_{\mathrm{CO}+\mathrm{O}} / \mathrm{k}_{\mathrm{CO}+\mathrm{Ar}}=15$

- Park (1994) T-T $T_{v}$ model

- $\mathrm{k}_{\mathrm{CO}+\mathrm{CO}} / \mathrm{k}_{\mathrm{CO}+\mathrm{Ar}}=10 \quad \mathrm{k}_{\mathrm{CO}+\mathrm{O}} / \mathrm{k}_{\mathrm{CO}+\mathrm{Ar}}=15$

- Johnston and Brandis (2014)

- $\mathrm{k}_{\mathrm{CO}+\mathrm{CO}} / \mathrm{k}_{\mathrm{CO}+\mathrm{Ar}}=10 \quad \mathrm{k}_{\mathrm{CO}+\mathrm{O}} / \mathrm{k}_{\mathrm{CO}+\mathrm{Ar}}=15$

- $\mathrm{k}_{\mathrm{CO}+\mathrm{Ar}(\mathrm{JB})} / \mathrm{k}_{\mathrm{CO}+\mathrm{Ar}(\text { Park })}=5$

- Objectives of our QCT rate coefficient calculations:

- Evaluate the accuracy of the experimental data used in the legacy model

- Determine these rate coefficient ratios as a function of temperature

- Study the importance of the exchange reactions in the shock layer 


\section{$\mathrm{CO}+\mathrm{Ar}$}

\section{After nearly all of the $\mathrm{CO}_{2}$ is dissociated, $\mathrm{CO}$ and $\mathrm{O}$ are the major species (with equal mole fraction)}

Experimental data

Davies (1964)

Appleton (1970)

$\mathrm{CO}+\mathrm{Ar}, \mathrm{CO}, \mathrm{O}$

Hanson (1974)

$\mathrm{CO}+\mathrm{Ar}, \mathrm{CO}, \mathrm{O}$

Mick \& Roth (1993) CO + Ar, CO

Park (1994) T-T $\underline{\underline{v}} \underline{\text { model }}$

\section{NASAAmes (2014-2015) QCT}

- Scatter in experimental data is small

- Very good agreement between QCT and Appleton and Mick and Roth expt.

- Fair to good agreement between QCT and Davies and Park (94)

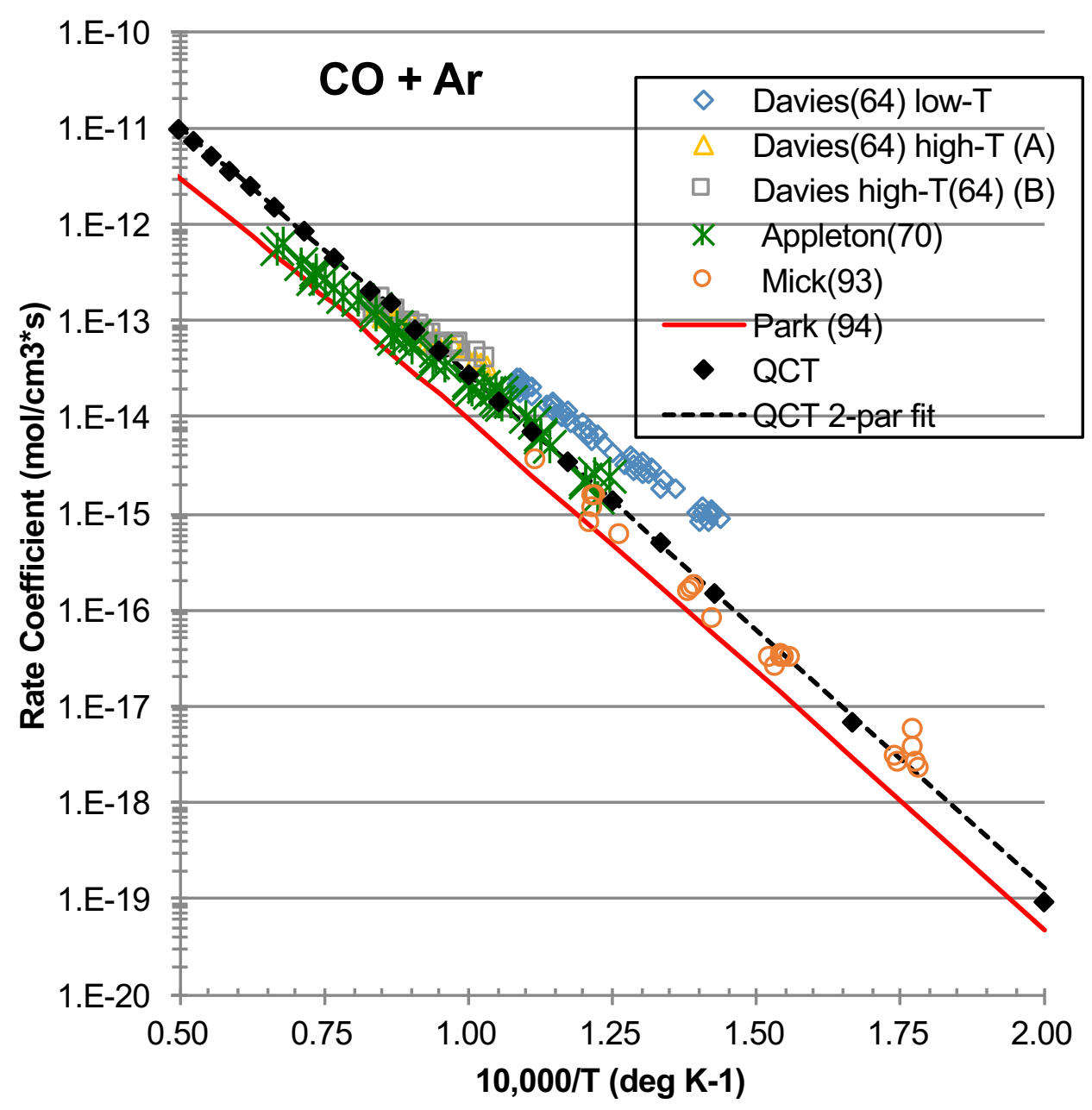




\section{$\mathrm{CO}+\mathrm{O}\left({ }^{3} \mathrm{P}\right)$}

- Three triplet PESs with equal statistical weight govern $\mathrm{CO}$ $+\mathrm{O}\left({ }^{3} \mathrm{P}\right)$ collisions

- Lead to different non-linear $\mathrm{CO}_{2}$ triplet electronic states $\left(1^{3} A^{\prime}, 1{ }^{3} A\right.$ " and $2{ }^{3} \mathrm{~A}$ ") with $\mathrm{O}-\mathrm{C}-\mathrm{O}$ angle $\sim 120^{\circ}$

- $1{ }^{3} \mathrm{~A}^{\prime}$ has well depth $\sim 75 \mathrm{~kJ} / \mathrm{mol}(\sim 0.8 \mathrm{eV})$; other states are more weakly bound

- Heterogeneous exchange reaction forming $\mathrm{O}_{2}+\mathrm{C}$ also possible on these PESs

- Reaction is endothermic by $6.1 \mathrm{eV}$ (low in comparison to the 11.2 $\mathrm{eV}$ dissociation energy of $\mathrm{CO}$ )

- All three PESs used for QCT calculations of CO dissociation and exchange reactions 


\section{CO + O Rate Coefficients (experiment)}

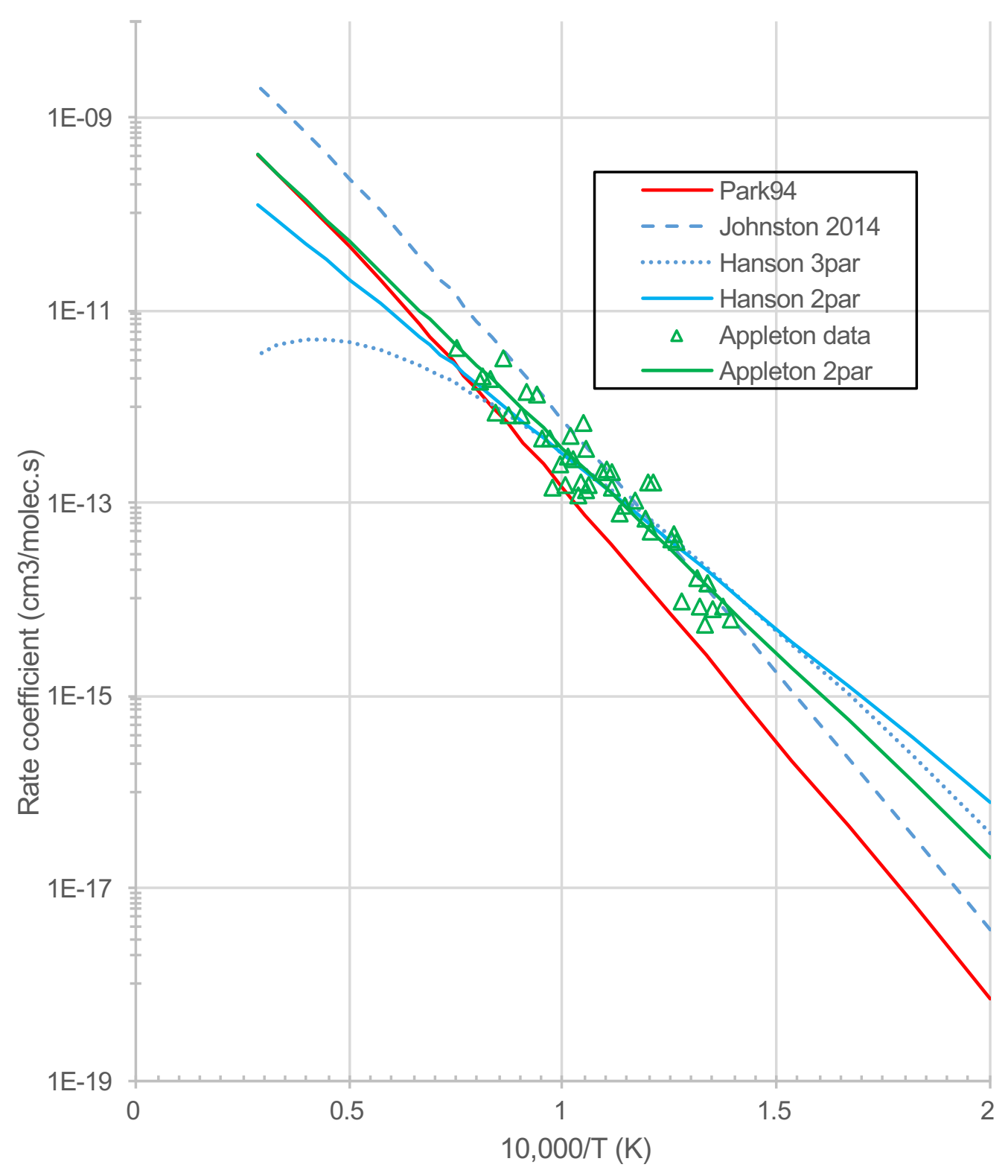

- Considerable scatter in the Appleton data

- Fairly good agreement between Appleton (8,000-15,000 K) and Hanson (5500-9000 K) data

- Hanson 3-parameter fit is not suitable for exptrapolation

- Park and Johnston recommendations bracket the experimental results 


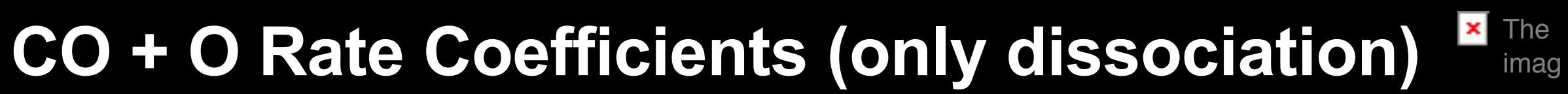

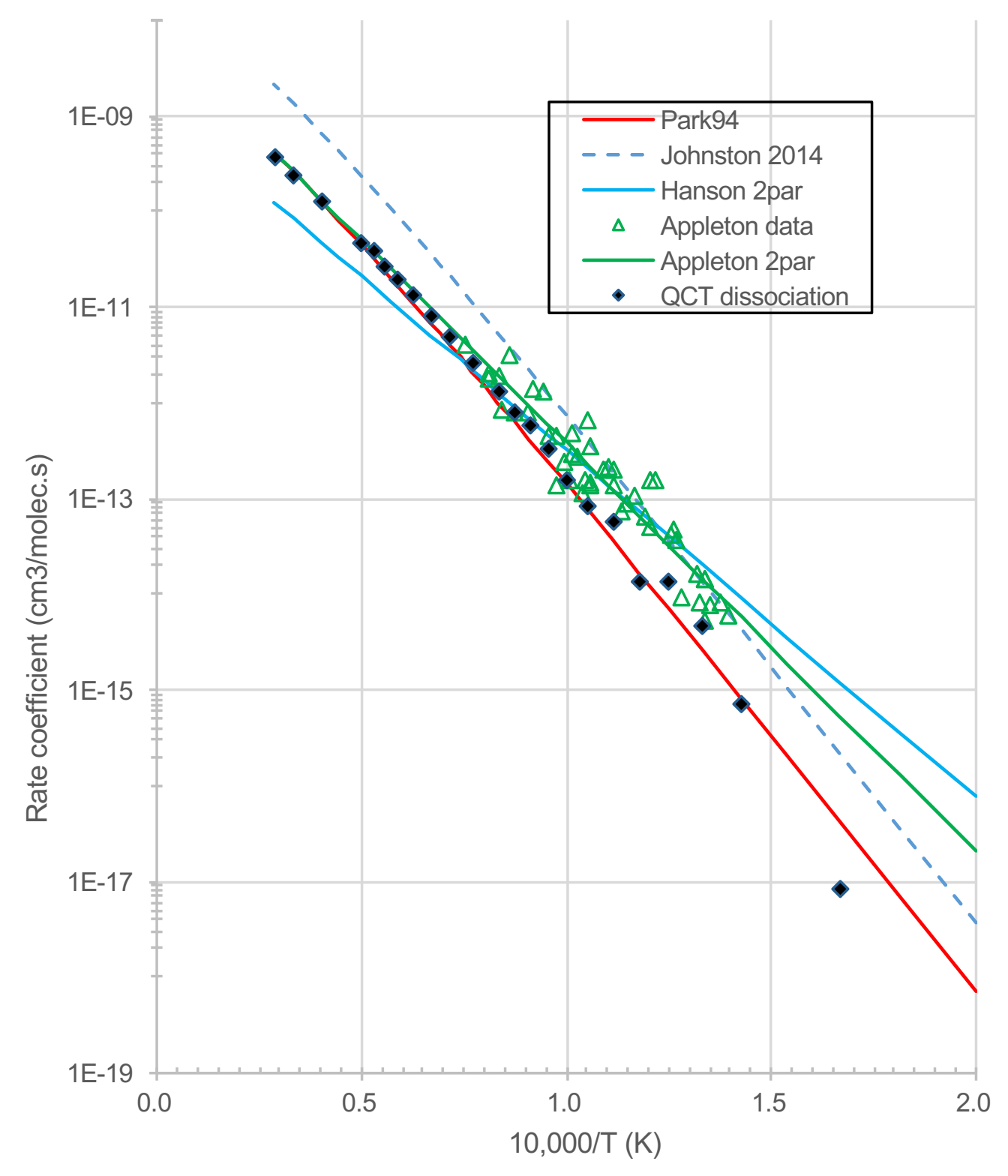

- Good agreement between QCT dissociation rate coefficient and Park model

- Agreement between QCT dissociation rate coefficient and expt is poor

- $\mathrm{k}_{\mathrm{CO}+\mathrm{O}} / \mathrm{k}_{\mathrm{CO}}+\mathrm{Ar} \sim 3-5$ for QCT not 15 as in Park model 


\section{CO + O Rate Coefficients (dissoc. + exchange)}

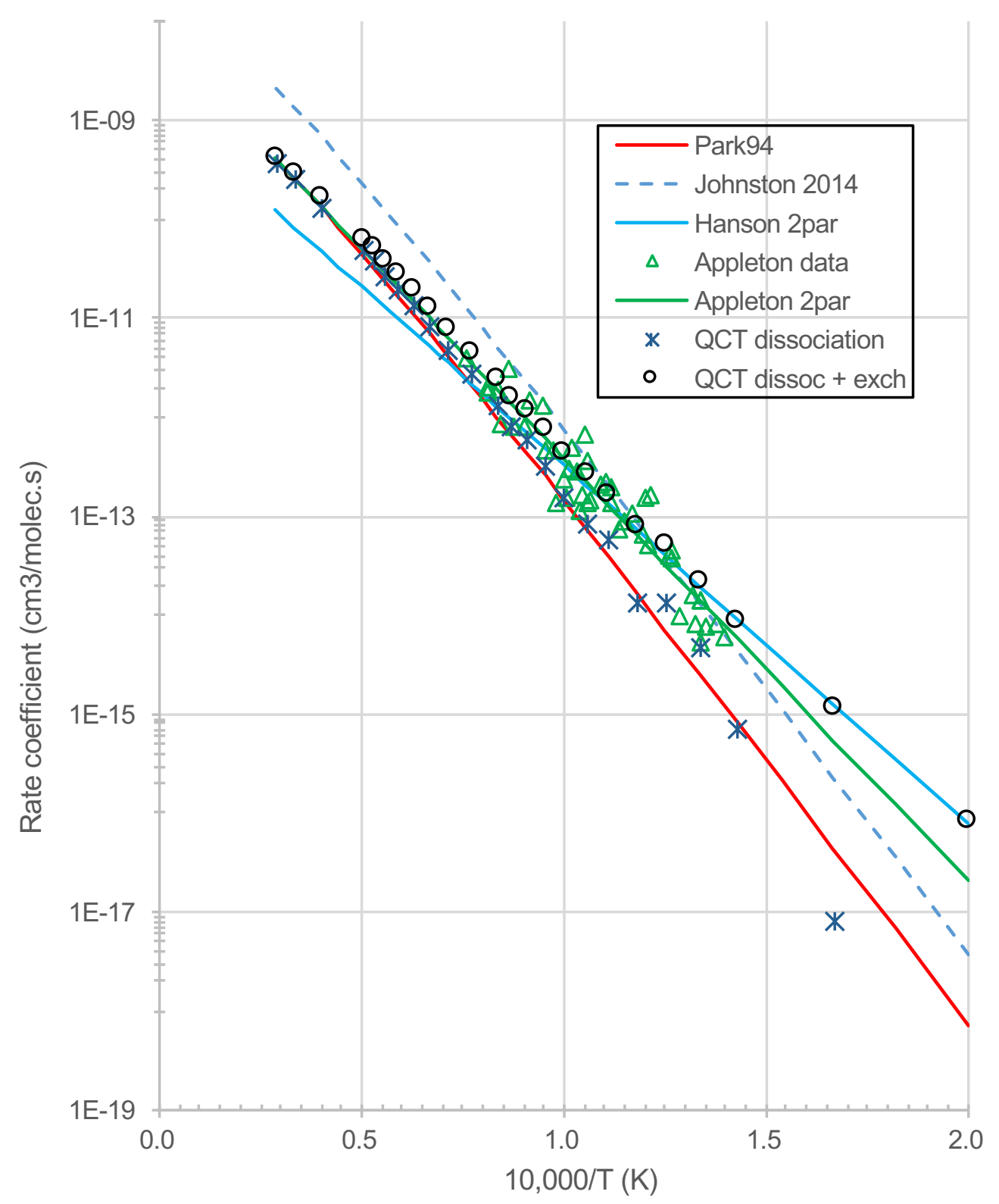

- Addition of hetero exchange rate coeff to dissociation greatly improves agreement with expt (especially at lower temperatures

- Good agreement with Johnston scaled value $\sim 8,000 \mathrm{~K}$, but temperature dependence is quite different

- Exchange is the dominant $\mathrm{CO}$ removal process for $\mathrm{T}<$ $8000 \mathrm{~K}$

This exchange reaction was not previously thought to be important 


\section{Key Points for CO Dissociation}

- Experimental data look quite good!

- However, it is advantageous to use experimental data points (if available), not just Arrhenius expressions

- Heterogeneous exchange reaction provides an important pathway for CO removal, especially for $\mathrm{T}<10,000 \mathrm{~K}$

- Converts $\mathrm{CO}$ to $\mathrm{O}_{2}$, which is readily dissociated at these temperatures

- Experimental CO dissociation rate coefficients implicitly include this reaction by having spuriously large dissociation rates and larger temperature exponents

- When combined with dissociation, agreement betwee QCT and experimental results is excellent

- QCT rate coefficients needed for $\mathrm{CO}+\mathrm{CO}$ to complete work on this set of reactions 


\section{Use in CFD Simulations}

- Used new rate coefficient data in simulations of convective heating for LENS XX shock tunnel tests

- Pure $\mathrm{CO}_{2}$ flow impinging on 12 " diameter model

- Flow enthalpies up to $43 \mathrm{MJ} / \mathrm{kg}$

- Compared Park94 model with new CO rate coefficients from present work to the Johnston modification of the original Park model in DPLR simulations
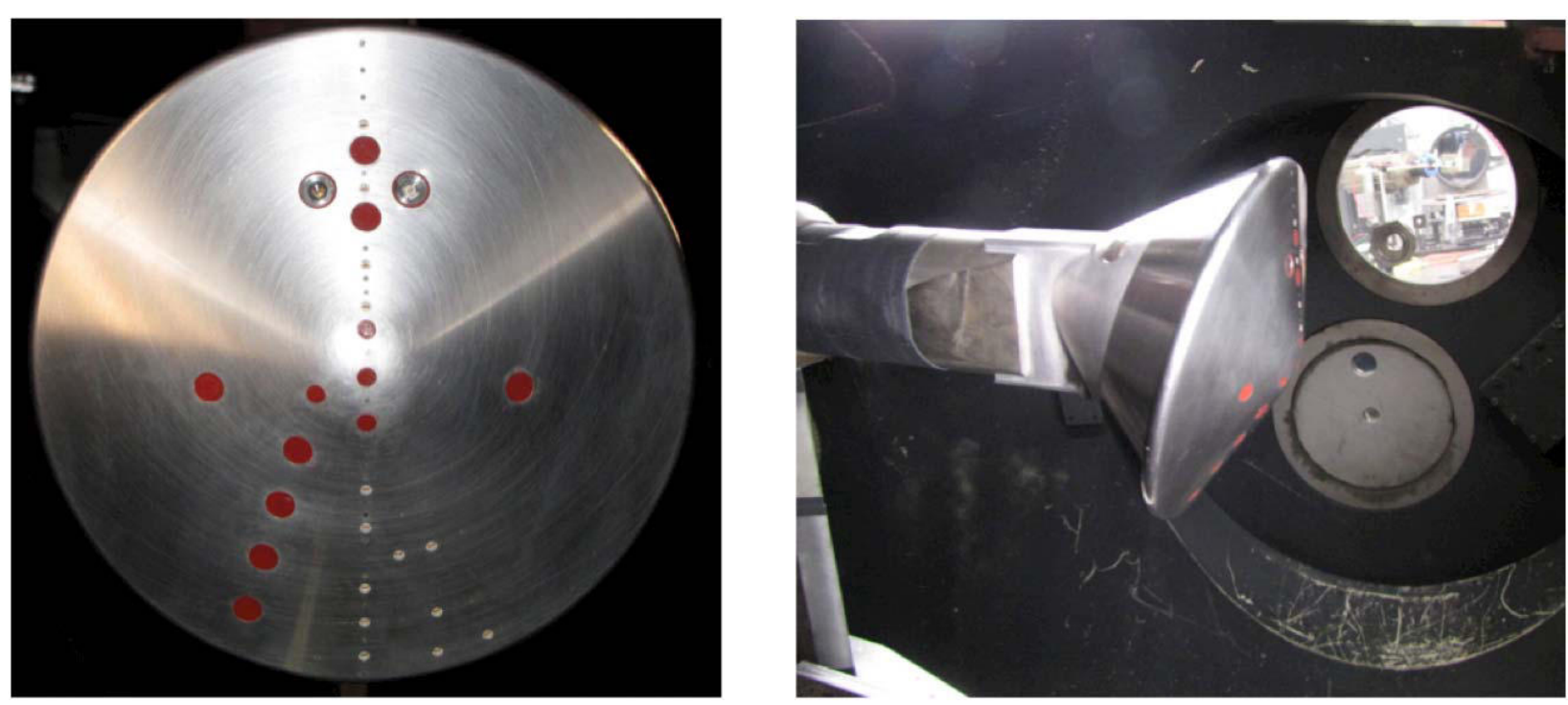


\section{Simulation vs LENS XX Test Data}

Moderate enthalpy (14.3 MJ/kg):

- Convective heat flux predictions for the models are barely distinguishable

- CFD and test data in good agreement

- This condition applicable to Mars entry
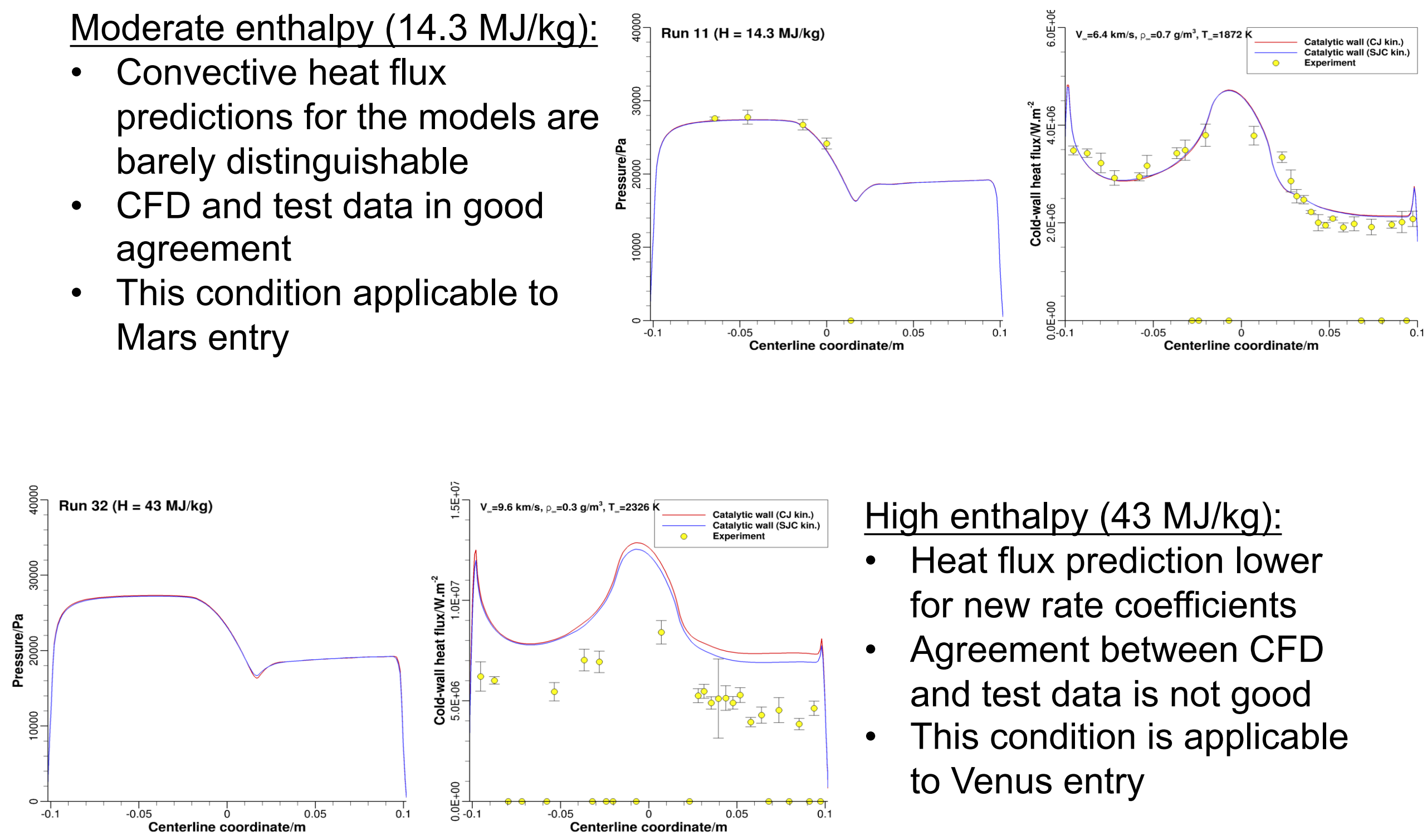

High enthalpy (43 MJ/kg):

- Heat flux prediction lower for new rate coefficients

- Agreement between CFD and test data is not good

- This condition is applicable to Venus entry 


\section{Use in CFD Simulations}

- Used new rate coefficient data in simulations of $\mathrm{CO} 4^{\text {th }}$ positive and $\mathrm{CN}$ violet integrated intensities from EAST tests

- $96 \% \mathrm{CO}_{2} / 4 \% \mathrm{~N}_{2}$ in Electric Arc Shock Tube at NASA Ames

- Flow enthalpy up to $43 \mathrm{MJ} / \mathrm{kg}$

- Compared Park94 with new CO rate coefficients from present work with Johnston modification and the original Park model in LAURAHARA simulations

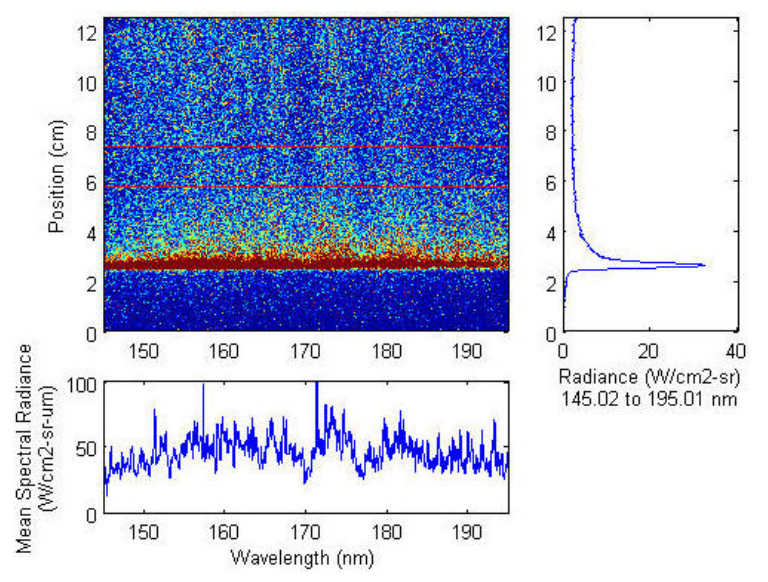

$\mathrm{CN}$ violet $"$ $\ll \mathrm{CO} 4^{\text {th }}+$

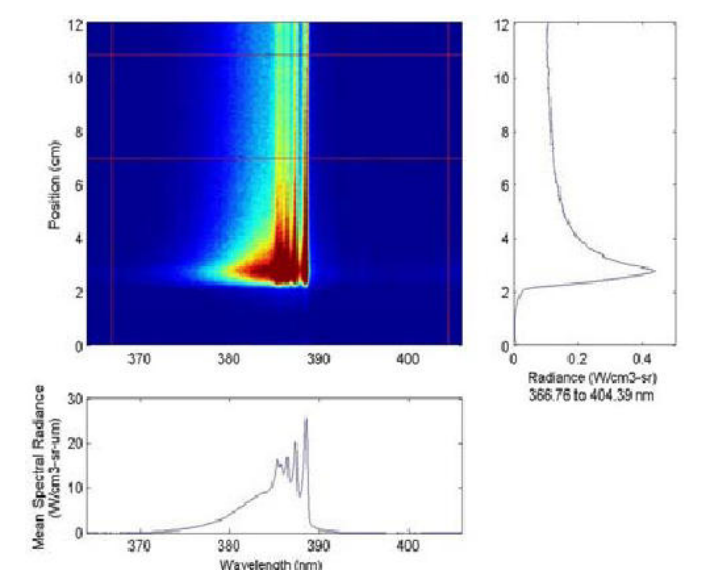




\section{Simulation vs EAST Test Data}

\section{$P_{0}=0.25$ torr and shockspeed $=6.43 \mathrm{~km} / \mathrm{s}$}
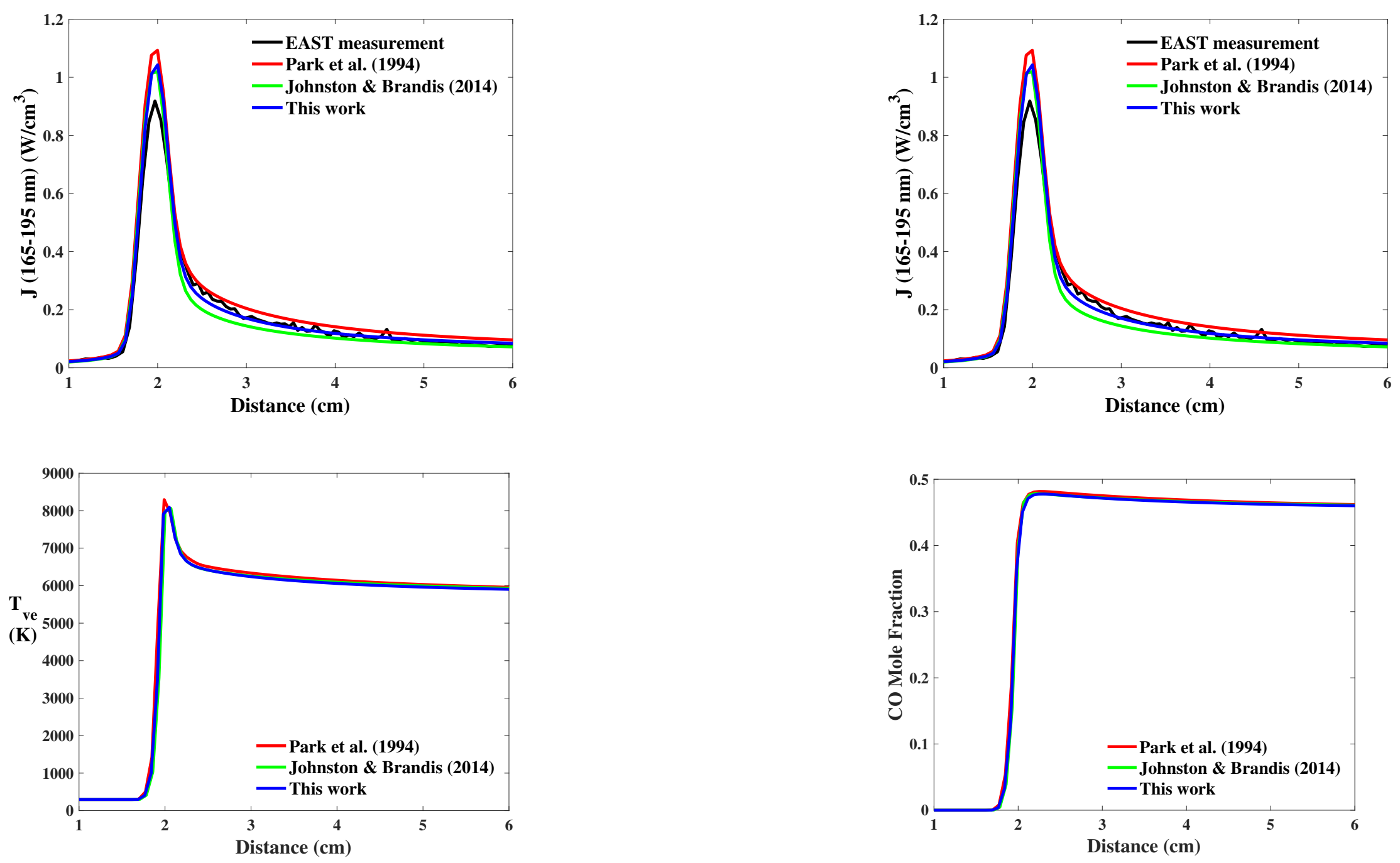


\section{Simulation vs EAST Test Data}

$P_{0}=0.1$ torr and shockspeed $=7.98 \mathrm{~km} / \mathrm{s}$
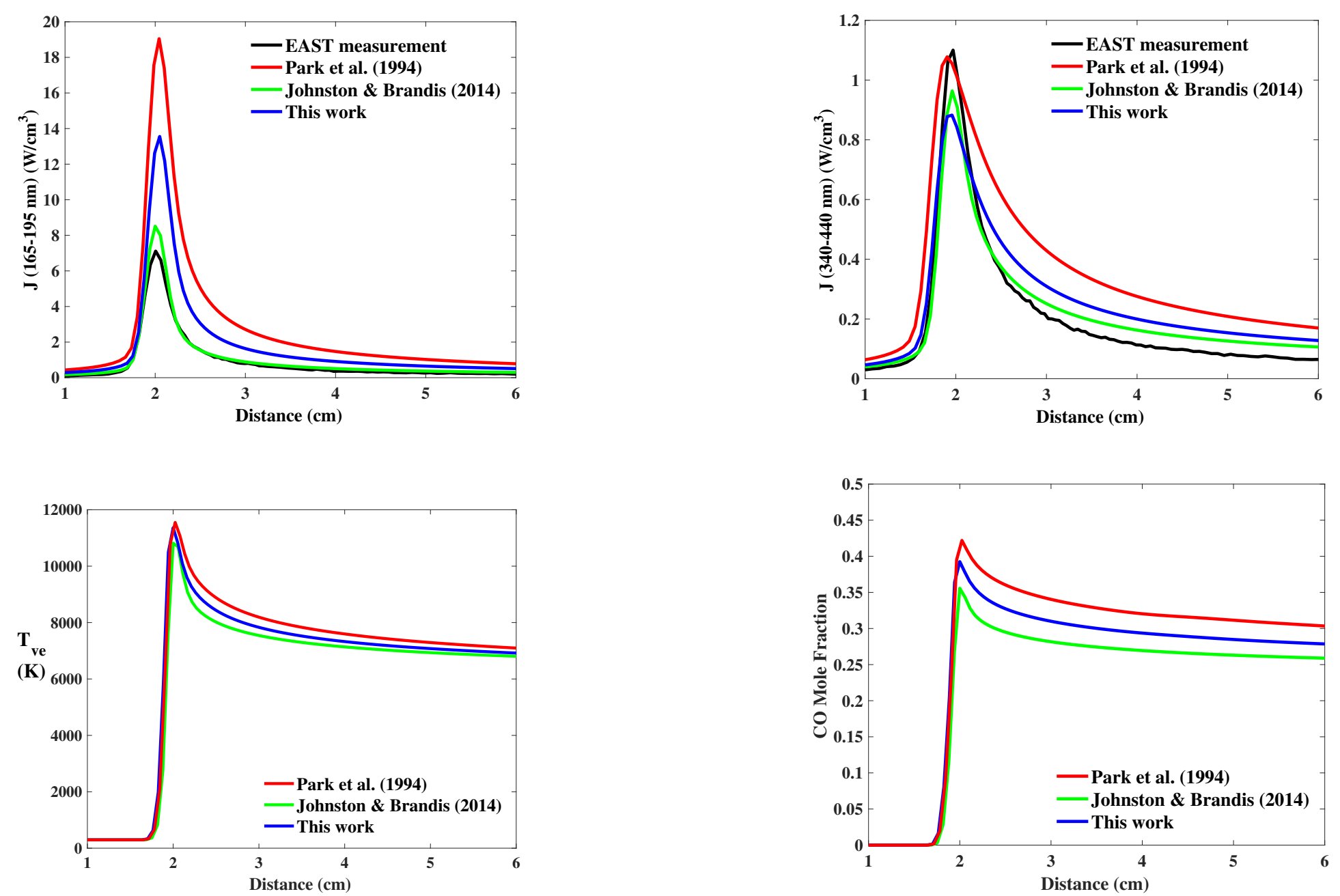


\section{On-going Work}

- Potential energy surfaces:

- PES for $\mathrm{CO}+\mathrm{CO}$ collisions to enable determination of rate coefficients for $\mathrm{CO}$ dissociation by $\mathrm{CO}+\mathrm{CO}$ collisions

- Rate coefficients:

- QCT calculations for $\mathrm{CO}+\mathrm{N}$ reactions forming $\mathrm{CN}+\mathrm{O}$ and $\mathrm{NO}+\mathrm{C}$

- QCT calculations for $\mathrm{O}_{2}$ dissociation and Zel'dovich reactions $\left(\mathrm{N}_{2}+\right.$ $\mathrm{O}$ and $\mathrm{NO}+\mathrm{O}$ ) using published PESs

- Analysis of quasi-steady state (QSS) models and internal energy relaxation $\left(\tau_{v}, \tau_{\text {int }}\right)$ using coarse-grained $Q C T$ methods developed by Prof. Panesi at $U$. Illinois at Urbana-Champaign

- Examination of alternative multi-temperature models and other approaches to describing nonequilibrium flows 


\section{Conclusions}

- The effort to create a new physics-based model for describing nonequilibrium phenomena in Mars entry flowfields is bearing fruit

- Potential energy surfaces and thermal rate coefficients for dissociation and exchange reactions have been computed for many of the important chemical reactions

- Independent calculations for $\mathrm{N}_{2}$ dissociation from two research groups show remarkable agreement

- Rate coefficients for different dissociation reactions show limitations and successes in the older data from shock tube experiments

- Work is progressing toward creation of a data base of QCT rate coefficients for the complete set of heavy particle reactions for modeling Earth and Mars entry

- Relaxation parameters $\left(\tau_{v}\right)$ and thermochemical data (specific heats, enthalpies and entropies) are also being computed

- We are also examining alternatives to the $T-T_{v}$ model using coarsegrained QCT calculations 


\section{Acknowledgements}

- Support from the Entry Systems Modeling Program (NASA Space Technology Directorate)

- NASA Collaborators

- David Schwenke

- Galina Chaban

- Winifred Huo

- Lu Xu

- U. Illinois Collaborators

- (Prof) Marco Panesi

- Simone Venturi

- Robyn Mcdonald

Mars tourism is coming!

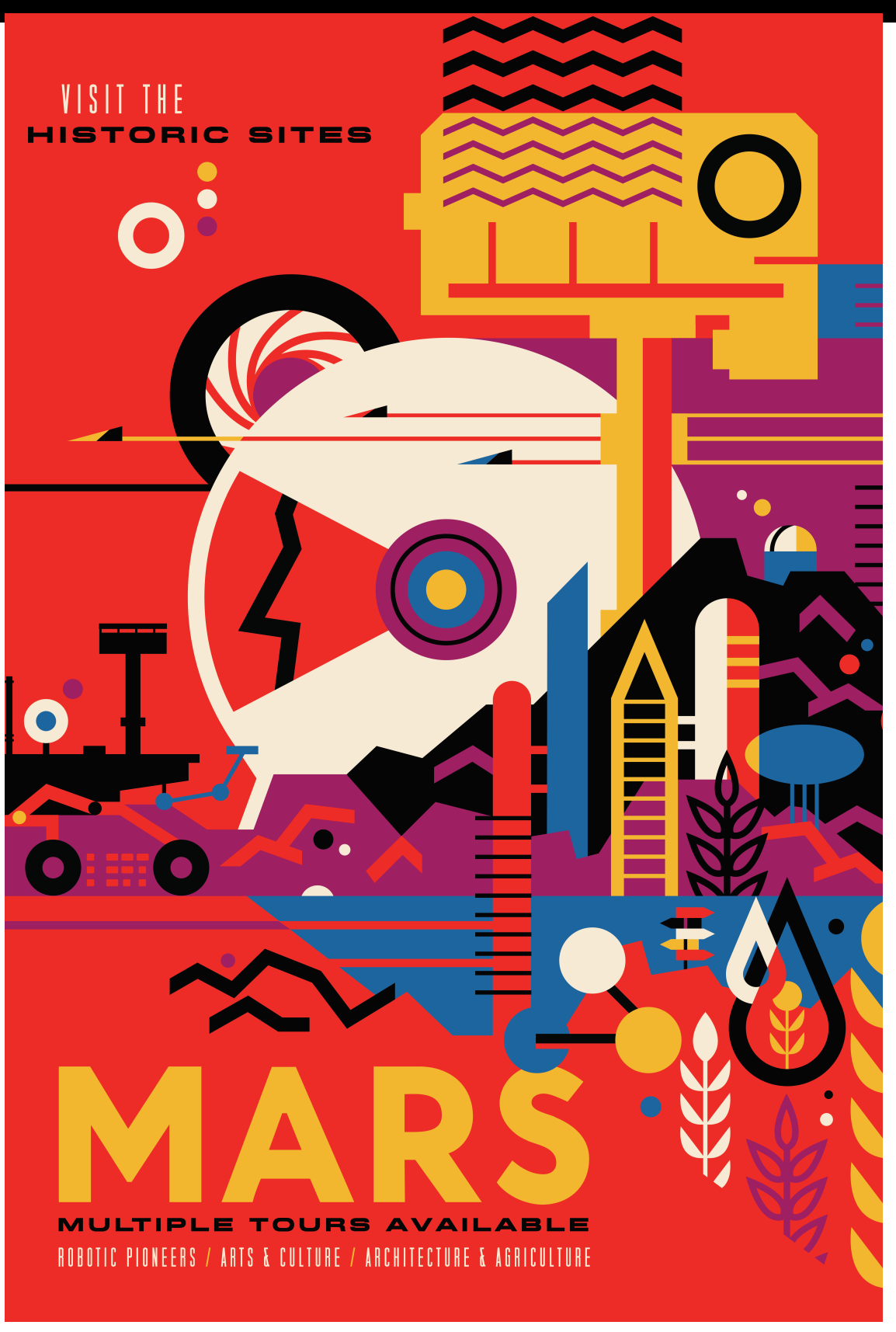

